\title{
On analysing the official statistics for antagonistic threats against transports in EU: a supply chain risk perspective
}

\author{
Daniel Ekwall
}

Received: 21 June 2010 / Accepted: 26 July 2010

(C) Springer Science+Business Media, LLC 2010

\begin{abstract}
The purpose of this paper is to analysis the risk for antagonistic threats against transports in EU in order to find patterns and trends. The research is based on a system-theoretical approach, which emphasizes a holistic view instead of the characteristics of the different parts. The research method used in this paper is deductive. The analysis is based on official statistics over antagonistic threats against transports in EU within a frame of reference consisting of theories from supply chain risk management and criminology. There is no silver bullet for solving antagonistic threats as it has always been a part of the business. Within this understanding there are many changes in hot spots, modus operandi, theft endangered objects and handling methods during time, but the basic theoretical frame of reference is still more or less the same. The geographically limitation to the EU is done of practical reasons whiles the frame of reference can be used globally for analysis antagonistic threats against transports. This research is limited by the lack of reliable information sources about criminal activities against logistics business. Secondary sources, like official crime statistics, are at best untrustworthy but more likely filled with large parts of hidden statistics. By using several different and independent official statistical sources and analysis the results within a common frame of reference can the validity of the research be secure. The theoretical framework is based on the theory of routine activity and its implications for logistics. This theory explains why the transport network produces the same theft opportunity over and over again.
\end{abstract}

Keywords Supply chain risk - Antagonistic threats · Cargo theft · Transport ·

Supply chain risk management $\cdot$ Terrorism

D. Ekwall $(\bowtie)$

School of Engineering, University of Borås, 50190 Borås, Sweden

e-mail: daniel.ekwall@hb.se 


\section{Introduction}

Business risk is commonly defined as the likelihood of a negative incident combined with the economic impact of that incident/source. The entire risk handling process is referred to as risk management. The usage of risk management tools and processes within the scope of logistics and supply chain management is defined by Norrman and Lindroth (2002) as: Supply chain risk management is to [collaborate] with partners in a supply chain applying risk management process tools to deal with risks and uncertainties caused by, or impacting on, logistics related activities or resources. According to Juttner et al. (2003), supply chain risk management is defined as "the identification and management of risks for the supply chain, through a co-ordinated approach amongst supply chain members, to reduce supply chain vulnerability as a whole". Both this definitions are general and therefore consider all risks and uncertainties without exception. This paper addresses a limited array of risks and uncertainties that are defined as antagonistic threats. Antagonistic threats are demarcated by three key words: deliberate (caused), illegal (defined by law), and hostile (negative impact, in this paper, for transport activities within the EU). According to Ekwall (2009a)) is: Antagonistic threats are deliberately caused illegal and hostile threats against the planned or wanted logistics process, function, and structure. Based on this definition, the core element for antagonistic threats are motivated perpetrators with hostile intentions toward the object and/or third party that violate an international, country, or local law. The antagonistic threat is therefore a crime and can be understood with the use of theories from criminology, or the scientific study of crime in combination with logistics theories. This leads to that this paper uses an interdisciplinary exchange of views, ideas, and theories which is needed to develop as an applied science (Klaus et al. 1993; Stock 1997).

\section{Background}

There is a significant problem with the theft of cargo worldwide. It is estimated that theft represents a loss of at least US $\$ 10$ billion per year in the United States and US $\$ 30$ billion worldwide (Barth and White 1998; Anderson 2007). These figures are calculated extraordinarily conservatively, since most cargo theft goes unreported and these figures reflect only the value of the items and nothing more (Barth and White 1998). There are predictions that the real figures for cargo theft are either grossly underestimated or overestimated in official reports (Gips 2006). The theft of cargo value for the European Union is estimated to be $€ 8.2$ billion annually, an average value of $€ 6.72$ per trip (EP 2007). Gathering accurate numbers for cargo theft losses is difficult or impossible in many cases, due to limited reporting by the transport industry and the lack of a national law enforcement system requiring reporting and tracking uniformity (ECMT 2001). Even the insurance business has problems separating fraud from real theft, but even if they had accurate numbers they would not share it with the public because of concern about trade secrets and competition. Despite these figures, cargo theft generally has a low priority status in most countries and is often perceived largely as the cost of doing business (EU 2003). No country, no commodity and no shipper are exempt from the acts of cargo theft (EU 2003). It has been shown that cargo theft is a grave threat to modern trade (EP 2007). 
Different preventive measures have been implemented to mitigate the problem of cargo theft, but the problem persists. According to Clarke et al. (2001) is there mainly two reasons for failures in crime prevention, firstly the unexpected use of new technology. Secondly, crime problems come from failure of people and organisations to prevent common crimes, which methods are well known and practical (Clarke et al. 2001). The reason behind this failure to prevent crimes arises from a number of reasons, like ignorance, lack of resources, unwillingness to expand resources and maybe even because that it is more profitable (or cheaper) to allow the crime than to prevent it (Sampson et al. 2010). This paper addresses the complex problem of antagonistic threat against transports in EU and why prevention of these threats fails.

\section{Research question}

The purpose of this paper is to analysis the risk for antagonistic threats against transports in EU in order to find patterns and trends, but also to analysis why the problem with antagonistic threats against transports in EU still exist despite all the different countermeasures implemented. This paper uses the perspective of supply chain risk management in the analysis which is based on official statistical data. The geographically limitation to the EU is done of practical reasons whiles the frame of reference can be used globally to analysis antagonistic threats against transports.

\section{Frame of reference}

Supply chain and the transport network

Christopher (2005) defines the supply chain as, "The network of organisations that are involved through upstream and downstream relationships in the different processes and activities that produce value in the form of products and services in the hands of the ultimate customer". These processes can be in different companies or in the same company. The different building blocks in a supply chain can, literally, be located throughout the world and connected through the use of a transport network. The transport network is designed to use economy of scale when moving products from consignor to consignee in a supply chain, through nodes and links. This means the transport network only physically integrates the supply chain with the fulfilment of its transport demands (Bowersox et al. 2002). Therefore, several different supply chains can be present at the same time and the same place in the transport network. This indicates that the relationship between supply chains and transport activities would be better described with complexity theory, especially if the interactions between components are the object of the research (Ekwall 2009a).

Looking at transport from a system perspective, we find that logistics is made up of different levels, infrastructure, resources and material known as the three levels of logistics (Lumsden 2006). A logistics system consists of links and nodes, where nodes are geographically fixed points such as factories and terminals, while the links are the elements connecting the nodes, i.e., the modes of conveyance. The flow of materials is the first level of the system, because it is the reason for the system's 
existence. Moving material from one place to another requires a flow of movable resources such as Lorries, trains, airplanes, and ships. These movable resources need infrastructure like roads, harbours, airports, and terminals (Wandel and Ruijgrok 1995; Ruijgrok et al. 1991).

The complexity in logistics can be explained by displaying the four flows always involved in logistics activities. The flows of material and resources are mentioned already. These two flows represent the "physical" part of logistics, but the other two flows, monetary stream and flow of information, are just as necessary to make the system work (Lumsden 2006). The four flows of logistics need geographical fixed constructions and infrastructure to fulfil the scope of logistics. Some of the infrastructure is owned and used exclusively by one company while some is coowned or owned by governments. The four flows of logistics and the necessary infrastructure are the five needs for logistics fulfilment (Ekwall 2009a).

The cargo thief aims to remove goods from the goods flow by attacking the movement of resources and/or the infrastructure it uses. A potential perpetrator can also utilize the information flow in order to better plan the theft of goods or commit a fraud which targets the flow of capital. This paper uses primary the three elements, flow of goods, movement of resources and infrastructure of the five needs for logistics fulfilments. The frame of reference uses the routine activity theory from criminology to explain the interaction between the transport network and potential perpetrators, where the theft opportunity is determent by each unique configuration of the five needs for logistics fulfilments and then exploited by a potential perpetrator.

Elements of crime and the routine activity

Criminology distinguishes three elements of a crime that are present in all sorts of crime ranging from occasional violence to advance and complex economic crimes (Sarnecki 2003; Sherman et al. 1989; Sampson et al. 2010). The elements are:

1. Motivated perpetrator

2. Target (goods and equipment)

3. Location (the place where perpetrator and object meets)

Motivated perpetrator The perpetrator is an individual that, based on the outcome of the decision process, commits a certain action or prepares for a certain action that is prohibited by locality or country of international law. The perpetrator can be modelled with two different categories depending on how decisions are made by each individual, namely rational choice theory (also known as the economical man theory) or determinism (Sarnecki 2003; cf Mankiw 1997). It is commonly agreed that different crimes demand various mixtures of rational choice and determinism from the perpetrator's side, where crimes of passion (sexual crime, etc.) are considered more deterministic than property crimes (economic crime, etc.), which are more rational. Thus, therefore can the general description of human behaviour be described as acting rational on the margin or limited (by circumstance, choice or mixture of both) rational choice.

Target The desirable outcomes or targets for the motivated perpetrator differ greatly depending on the motivated perpetrator's decision process. Normally is it suitable to 
describe the target as the primary or direct reason for the action, but also as secondary or indirect reasons. The primary targets can be shipped products, resources used, and infrastructure for normal property crimes but for terrorist crimes are the target defined differently. For a terrorist is a targets symbolic value and political meaning that qualify it as suitable, not its economical value (Napoleoni 2004; Peste 2003; Kimball 2002; Rystad 2006). The modern or new thing with terrorism is not the use of violence to influence and alter the current balance of power in a certain direction. This has always been the goal with terrorism. The new thing with terrorism is therefore more related to development in media technologies than to vulnerabilities in supply chains.

Location The location or place where the motivated perpetrator and the target meets. The characteristics of the location include different security measures or crime preventive features directly linked to the location. A good example of this is CCTV surveillance of areas may lead to a relocation of the crime instead of prevention of it (Weisburd et al. 2006; Waples and Gill 2006; Tilley 1993).

Most important to remember about the elements of crime is that it is first when all three elements comes together at the same time that a crime is possible. This means that if one of the three elements is missing than is crime impossible. Any combination of location and target are normally referred to as a crime opportunity. According to Clarke and Cornish (2003) are both a motivated perpetrator and a crime opportunity needed in order for a crime to occur. The theory of crime opportunity also refers to the fourth principle of microeconomics (Mankiw 1997) people respond to incentives - and there the degree of necessary opportunity or incentive depends on the individual. The incentives could range from vindication to morality, ethics, altruism, or determinism.

According to Felson and Clarke (1998) are "Crime opportunities depend on everyday movements". Restated, crime opportunities depend on routines or predictability within certain boundaries. This statement also includes more principles than the original, implying that system predictability or routine provides crime opportunities. This is the routine activity perspective in criminology (Cohen and Felson 1979). This theory provides a strong theoretical foundation for understanding crime and opportunities for crime. The routine activities perspective argues that normal movement and other routine activities play a significant role in potential crime (Roncek and Maier 1991; Mustaine and Tewksbury 1998; Smith et al. 2000; and Sherman et al. 1989). The routine activity theory states that potential perpetrators may seek locations where their victims or targets are numerous, available, convenient, and/ or vulnerable. Felson (1987) uses the illustration of "how lions look for deer near their watering hole" to explain the practical relevance of the routine activity perspective. According to Smith et al. (2000), social disorganization in combination with the routine activity theory can provide a wider and better explanation of property crime.

The movement of resources between terminals, factories, and other nodes also is predictable to a large extent. The routine activity perspective states that predictability in infrastructure and resource movement will significantly contribute to establishing crime opportunities. The flow of material varies to a higher extent but depends on the actors within the supply chain. Therefore it is possible to predict the flow of 
goods to some extent. The routine activity perspective provides a theoretical foundation regarding antagonistic threats against transports in EU. Thus, when the transport network changes, so does the theft opportunity.

\section{Hot products}

The term hot products are commonly used in shrinkage management and its purpose is to point out a particular item or product as hot. These products are more likely to be stolen and therefore need greater attention in surveillance (Beck and Chapman 2003; Sherman et al. 1989). According to Clarke (1999), hot products are defined as products that are CRAVED: Concealable, Removable, Available, Valuable, Enjoyable, and Disposable. Which products are hot is often based on assumptions and opinions, but rarely by robustly derived data (Beck and Chapman 2003). By using accurate data factors such as opportunity and the black-market prospects, each item will be considered on equal basis as the pure value of the product (ECR 2003).

\section{Terrorist threats}

The word "terror" is a Latin word meaning "to frighten." Consequently, a terrorist is a person that intends to frighten others through fear. The term terrorist/terrorism is itself controversial because its key signature is political and it has been used by states to illegitimatize political opponents. This leads to a vindication of the state's own use of terror against its opponents (Napoleoni 2004). The lack of a universal definition of terrorism is one of the major obstacles for meaningful international countermeasures. The practical consequence of this is best explained with the cynical comment "that one state's terrorist is another state's freedom fighter" (Burns and Peterson 2005). Regardless, this thesis uses the terrorism definition by TE-SAT (Europol 2007), which says, "Terrorism is not an ideology or movement, but a tactic or a method for attaining political goals".

The World Trade Center terror attack in 2001 changed the world and the conditions for logistics worldwide. The aftermath of the terrorist attacks clearly indicated that logistics operations will suffer consequences of an attack. The logistics consequences according to Sheffi (2001) were, "It is instructive to note that these disruptions were not caused by the attack itself, but rather by the government's response to the attack: closing borders, shutting down air traffic and evacuating buildings throughout the country" Therefore, the antagonistic threat from terrorism can cause consequences indirectly for logistics operations, which economically driven antagonistic threats are less likely to involve. With this said, antagonistic threats in the form of terrorism will also indirectly affect the financial market (Johnston and Nedelescu 2006; Lowe 2006). The effects from attacks will fluctuate depending on factors such as the nature of the attacks, the multiplier effects, the type of policies adopted in response to the attacks, and the resilience of the markets (Bruck and Wickstrom 2004).

Johnston and Nedelescu (2006) state that, "over the longer term, there is a question of whether the attacks can have a negative impact on productivity by raising the costs of transactions through increased security measures, higher insurance premiums, and the increased costs of financial and other counterterrorism regulations". The connection between economically and non-economically driven antagonistic threats can vary 
and in some cases directly depend on each other, because "terrorist organisations raise funds through legitimate and illicit activities but more commonly through a mixture of both" (FATF 2010). The principle driving force behind a terrorist attack is normally more diverse than an economically driven antagonistic threat (Nuzzo 2004).

The motivation for the majority of terrorist attacks is because the perpetrator intends to influence and alter the current balance of power in a certain direction (Rystad 2006). Both the current balance of power and the potential affects on it may only be understood within the perpetrator's own mind. Therefore, the non-economically driven antagonistic threat is more nuanced, uncertain, and harder to predict that other types of antagonistic threats. According to Sjöberg (2008) the fear for terrorist attacks is an extreme form of perceived risk. The definition of terrorism influences the difficulty to present valid statistics for the category, because one source may classify an incident as a terrorist act while another considers it to be a "regular" crime.

\section{Transport security}

According to Borodzicz (2005) security can be considered as interpreted as either freedom from danger or a show of force (or strength). Both interpretations are valid for this paper but in normal life is the last meaning of the word security more common. According to Closs and McGarrell (2004), three factors for security in trade can be outlined: first, the globalization of world trade depends on and is generated by the free flow of people, goods, and information; second, the increasing demands from businesses for efficient supply chain operations; and third, the increasing threats of terrorist attacks. This factor can define illegal and antagonistic threats, of which terrorists are one type.

Present supply chain security research outlines several changes for how security in a supply chain should be approached. First, supply chain security should incorporate not only theft prevention but also anti-terrorism measures. Second, the focus is now on global issues and not just local or national issues (Sweet 2006). Third, when conducting contingency planning, the concept of crisis management is to be included to obtain better resilience. Last, security is no longer an internal corporate question but rather an issue for all actors within the supply chain (Closs and McGarrell 2004). Important to remember is that the causes for antagonism can be described as a spiral of inputs, processes, and feedback, which explains the dynamics of antagonism. Such dynamics tend to make analysis, assessment, and decision very complex, and the world seems to be anything but deterministic (Manunta 1999). Understanding antagonistic dynamics is vital for an analysis of where, when, and how the protector shall be to prevent adverse events from occurring. This leads to that security shall address the dynamics of antagonism by understanding the environment or context of the threat instead of only reacting to official statistics. The context of a risk should be understood as partly perceived and partly objective, and any actor that manages the risk needs to consider its context (Waring and Glendon 1998). In order to understand the context shall both the view-point of the supply chain as well as the potential perpetrator be included in the analysis. This leads to the idea that security should be integrated throughout the entire supply chain to be successful. This opinion is supported by several other authors (Borodzicz 2005; Ritter, et al. 2007; Sarathy 2006; Closs and McGarrell 2004; Rice and Spayd 2005; Manuj and Mentzer 2008; Lee and Whang 2003; Ekwall 2009a). 
Antagonistic threats against transport

The frame of reference uses the routine activity theory from criminology to explain the interaction between transport and potential perpetrator, where the theft opportunity is determent by each unique configuration of the flow of goods, movement of resources and infrastructure of the five needs for logistics fulfilments. The primarily objective of transport security is to protect the goods (target) but also to safeguard locations. The system theoretical and deductive model used in this thesis is presented in Figure 1.

\section{Method}

The research method used in this paper is deductive; hence, a hypothesis is developed by logical deduction from existing theories. This paper's hypothesis on antagonistic threats has been developed from theories of criminology, for applicable use, to strengthen the scientific field of logistics (Stock 1997). Credibility is substantiated by verifying the deductive hypothesis with two different methods, so called methodology triangulation (Mangan et al. 2004). The first step used official statistics from several independent sources in both macro (national, state or bigger geographical areas) and micro (county or smaller geographical areas) levels to describe the general risk level (criminal risk level) in the different EU countries. The second step uses specific criminal statistic describing the reported threats against the transports in the EU. A combined analysis is preformed and compared with the deductive hypothesis which leads to the answers of the research questions in this paper. The research in this paper follows the tradition in logistics of using a system approach to answer research questions (Aastrup and Halldórsson 2008; Hellström 2007; Gammelgaard 1997; Gammelgaard 2004). The main idea of system theory is to illuminate holistic thinking; it is based on the assumption that a whole system is different from the sum of its components (Churchman 1968; Von Bertalanffy 1969; Hellström 2007). This paper uses a hard system approach (Checkland 1999) which implies both an objective reality and a top-down perspective on the system in order to how the different elements interact with each other (Hellström 2007).

The validity and credibility of the research depends on the use of data and the sources of this data. The data used in this paper are from different independent secondary sources as literature, databases, official criminal statistics and reports. The

Figure 1 Antagonistic threats against transport

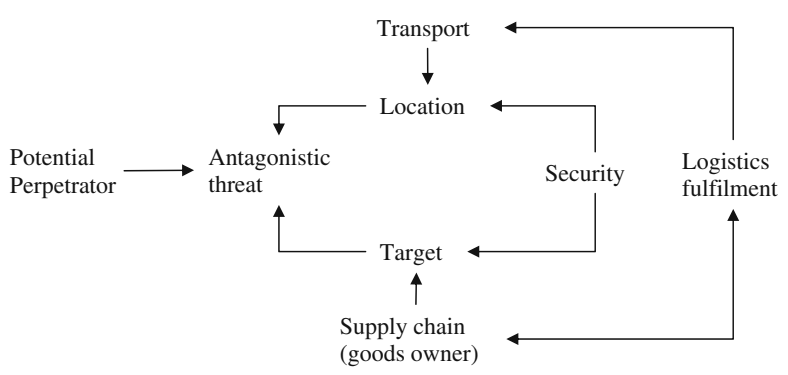


main problem with secondary data is explained with the question of where and when it was transformed from primary to secondary data. The difference can appear small, but when the data is used it can affect the entire study, therefore is this paper based on data triangulation as primer method of analysis data. Official criminal statistics are questionable because they contain actual and unsubstantiated crimes but omit unreported actual crimes (Lab 2000). The secondary data from reports was collected from trustworthy institutes such as the Europol, and the European Commission. In some cases the report came from a trade association.

\section{Empirical findings}

\section{Official macro statistics}

The usage of general statistics (mainly different types of criminal statistics) can provide a hint about the general criminal threat in a country or local area. This fact is well known. Sometime is the relationship between reported crimes and public fear of crime direct whiles other times more indirect. Thus, it is possible that inverts that relationship and use macro level statistics in order to hint criminal hotspots in general. Important to remember is that this only provides a general hint about criminal threats and this clearly limited the possibility to draw far-fetched conclusions unless more detailed data is added. This paper uses this possibility. A good indicator for criminal threats and common distrust in the society is level of corruption in a country (Francis 1986). This paper uses corruption as an indicator of distrust in official statistics, were Denmark are the least corrupted country (index 9.7) whiles Bulgaria, Greece, Romania are the most corrupted (index 3.8) (Transparency, 2009). A good indicator of the violence present in a society is the number of homicides per 100000 citizens (lower number means safer). The safest country in the EU is Denmark (0.53) whiles the dangerous country is Estonia (6.79) (UN 2002). This shall be compeered with the average homicides rate 2007 in EU which is 1.4 in general but increases to 1.9 in capital cities (Eurostat 2009). Other good indicators of criminal threats are the reported total number of crimes as well as the reported number of thefts and robberies. Risk rating (both relative and absolute) are good indicators on more transport related crimes. It is important to remember that each country may (are likely to) have different definition of crimes and guidelines for data collection.

The general criminal trend in EU is that crime is declining from the pike around 1995. According to (Eurostat 2009) have their being an increase in reported crimes types violent crime (up 3\%), drug trafficking and robbery (both up 1\%) in the period 19982007. During the same period has seen a decrease in motor vehicles (down 7\%) and domestic burglary (down 3\%). Their seems to be a time difference between countries in the decline but the trend is nevertheless declining and even criminal patterns are surprisingly similar between member states (EUICS 2005). The reason for this decline is according EUICS (2005) the "changing demographics, among other factors, have played a causal role in the decreases in crime across the Western world. Since the bulk of common crimes are committed by young males". There is also a suggestion that the better policing and/or more severe sentencing contributes to the declining criminal trend (EUICS 2005). The different official statistics supports these conclusions. The country with the highest risk for antagonistic threats according to official statistics is 
UK whiles countries like Bulgaria, Greece, Romania, Italy, Latvia, Lithuania, Slovakia are the most corrupted (Transparency, 2009).

Shrinkage in transport

The term inventory shrinkage is the loss of products between the point of manufacturing or purchase from supplier and the point of sale. According to the report, "National Retail Security Survey" (NRSS 2002), the average shrinkage rate is $1,8 \%$ of total annual sales. This means a total loss of $\$ 33,21$ billion annually in the U.S. The report points out four major sources of shrinkage: employee theft, shoplifting, administrative error, and vendor fraud. Therefore, three of four sources for shrinkage are criminal actions. The losses in the European fast moving consumer goods are for $26 \%$ in manufacturing, $8 \%$ in distribution, and $66 \%$ in retail (ECR 2003). Shrinkage during distribution/transport is approximately $0,14 \%$ of annual sales for all types of products. The report, "TAPA Loss Data Benchmark Survey 2006" (TAPA 2006), states the worldwide loss ratio as $0,025 \%$ of the total revenue ( $\$ 307$ billion revenue and $\$ 77$ million in losses). Benchmark participant loss rates varied from 0 , $0038 \%$ to $0,25 \%$ of total revenue. The four different reports (NRSS 2002; ECR 2001; ECR 2003; TAPA 2006) indicate that the annual shrinkage during distribution/ transport would be $0,025 \%$ to $0,14 \%$ of annual sales. This loss ratio is compared with the loss ratio for retailers $(1,75 \%)$ and manufacturers $(0,56 \%)$ (ECR 2003).

The losses presented according the mode of transport gives the following result (TAPA 2006): truck $(74,6 \%)$, air $(23,1 \%)$, rail $(0,8 \%)$ and sea $(1,5 \%)$. This survey indicates two conclusions. First, the risk for losses varies greatly between different modes of transport. There is no surprise that truck and air combined represent $97 \%$ of all losses, since they are the primary modes of transport for the survey participants, depending on their high-value goods. However, that does not explain the huge difference between the modes. The different specific criminal statistics regarding cargo theft clearly points out road transport as the most target mode of transport. This may depend on that road transports are both simplest (in general) to target but also the most occurring mean of transport.

Specific criminal statistics-terrorism

Reviewing official terrorist statistics from one global source (MIPT Terrorism Knowledge Base) leads to the following transport related conclusions:

- Transport activities represent 4\% of the targets in 2006 and 5\% in 2007.

- The main modus operandi for attacks is armed attack (38\% 2006 and 31\% 2007) and bombing (51\% 2006 and 54\% 2007).

- The main area for terrorist attacks are Middle East/Persian Gulf (68\% 2006), and Asia (24\% 2006).

The terrorists prefer to use bombs and armed attacks because $80-90 \%$ of all attacks used these tactics. The targets are rarely transports but more in form of police and other governmental or religious institutions ( $\sim 53 \%$ of the attack 2006$)$. The interesting feature is related to the geographic side of terrorism, because the terrorist 
threat is mainly linked to local/country/regional contexts. The new "trend" (post-9/ 11 terrorist attack) in terrorism is to transfer local terrorist contexts to a regional or global perspective. This effect is incredibly difficult to verify with statistical sources, but the terrorist threat is still linked closely to regions in the world. One of the biggest difficultness with statistics about terrorist attacks is to separate terrorist attacks from attacks civil war attacks, especially in low intense conflict countries. The separating of terrorist incidents from incidents in conflict zones is even difficult from a theoretical point of view. The general conclusion is that the risks from terrorists are primarily locally/nationally/regionally linked and they prefer to attack non-business related targets using armed attacks or bombs.

The risk for terrorist attacks in EU is also closely linked to locally/nationally/ regionally situation. About $85 \%$ (2006) of the reported terrorist attacks were linked to different separatist movements in primarily France $(55 \%$ of all attack in EU occurs in Corsica) and Spain. Whiles another 13\% (2006) of the attacks was linked to left of right wing movements. In both cases is it clear to state that the current government are the main target and the terrorists wants, by inducing fear into people, alter the current balance of power in their regions.

The modern or new thing with terrorism is not the use of violence to influence and alter the current balance of power in a certain direction. This has always been the goal with terrorism. According to Gearson (2002) is: "Terrorism in all its forms, by its very nature, an asymmetrical response to superior force, and terrorist have always used their capabilities as force multipliers-usually through the exploitation of terror. The generation of fear, in effect the use of purposeful violence as a form of psychological warfare can now be carried much further, enhanced by the modern media and the proliferation of mass media as much as by the proliferation of weapons". The new thing with terrorism is therefore more related to development in media technologies than to vulnerabilities in supply chains. Nevertheless, terrorism is a special form of antagonistic threat that needs to be managed, in one way or another.

\section{Specific criminal statistics - road transport}

According to the ECMT (2002), approximately 1\% of all commercial vehicles in European countries are stolen each year. The development differs greatly between different countries in the EU. The average increase during a five-year period (19951999) was $20 \%$. There are many reasons behind a truck theft, but they can be described basically with three main characteristics - value, cargo carrying ability, and valuable documents. The first characteristic, value, represents the truck's value as all objects and can be sold and exchanged for money. The second characteristic, carrying ability, refers to the general propose of a truck. The vehicle and its load were targeted in $63 \%$ of the attacks (IRU 2008), and in $10 \%$ of all freight crimes are hijackings (Robinson 2009). The truck can be stolen with the current load where the goods are the desirable object and the truck is only the simplest method to move the goods to a warehouse or to another truck for further movement. A truck also can be stolen for other criminal activities.

The third characteristic of theft problems toward freight is the attack for the lorrydriver's private property or other types of valuable documents such as credit cards, 
mobile phones, and digital cameras stored in the truck during transport. The lorrydriver's private property represents the target in 43\% of all attacks (IRU 2008). According IRU (2008), 17\% of all drivers suffered an attack during the past five years, $30 \%$ were attacked more than once. Of all drivers attacked, $21 \%$ reported they were physically assaulted during the attack (IRU 2008). According to Dillén and Ekwall (2006), this type of attack represents a considerable amount of the total, but nothing was stolen in $38 \%$ of attacks against trucks. However, even if nothing was stolen it was still a crime against a part of the transport network and therefore shall be seen as an antagonistic threat. Seventy percent of attacks against road transports occur between 22:00 in the evening and 06:00 in the morning (IRU 2008). This trend is also found in official Swedish criminal statistics (Nilsson and Rosberg 2009). Therefore, it is possible to state that time of day plays an important role in antagonistic threats.

Regardless of which of the three characteristics of theft problems the motivated perpetrator uses, there is a number of commonly defined modus operandi or methods to attack trucks. These different modus operandi are used differently depending on where the attack is executed. The different locations are described in terms of different steps in a transport from consignor to consignee, which starts with loading the goods and ends when unloading them. Eurowatch has developed a threat/risk matrix based on the data on cargo theft in transports (mainly road transports) over a seven-year period (Robinson 2009). The matrix presented in Table 1 maps modus operandi and location of attacks against each other.

A quick analysis of the matrix points out some obvious relationships. The method fake accident is best suited to deceive a truck driver to stop during driving and then conversion to a hijack. The same course of events can be created with the use of fake police tactics. The threat/risk matrix points out the most dangerous location to be near end location or at insecure parking depending on which modus operandi is considered most threatening. Therefore, location plays an important role in antagonistic threats.

The greatest source of risk for businesses is trusted insiders (Barth and White 1998). Some authors consider insiders to be involved in approximately $60 \%$ of all losses (Tryon and Kleiner 1997). According to Robinson (2009) is 65\% of all "whole load losses" related to the use of inside information. Others claim there are no reliable figures (Muir 1996). This is interesting when considering the fact that

Table 1 Threat/risk matrix, transport using Eurowatch data 2002-2009, 4 represents the highest risk (Robinson 2009).

\begin{tabular}{|c|c|c|c|c|c|c|c|}
\hline & Hijack & Robbery & $\begin{array}{l}\text { Theft from } \\
\text { vehicle }\end{array}$ & $\begin{array}{l}\text { Theft of } \\
\text { vehicle }\end{array}$ & $\begin{array}{l}\text { Fake } \\
\text { police }\end{array}$ & $\begin{array}{l}\text { Fake } \\
\text { accident }\end{array}$ & Deception \\
\hline Load point & 2 & 3 & 2 & 3 & 1 & 1 & 4 \\
\hline Driving & 4 & 1 & 1 & 1 & 4 & 4 & 2 \\
\hline $\begin{array}{l}\text { Insecure } \\
\text { parking }\end{array}$ & 2 & 4 & 4 & 4 & 3 & 1 & 2 \\
\hline Secure parking & 2 & 2 & 3 & 3 & 1 & 1 & 2 \\
\hline $\begin{array}{l}\text { Near end } \\
\text { Location }\end{array}$ & 4 & 3 & 3 & 4 & 3 & 1 & 3 \\
\hline Unload point & 2 & 3 & 2 & 3 & 1 & 1 & 4 \\
\hline
\end{tabular}


most countermeasures are implemented to reduce external theft (Beck 2002). An internal perpetrator acts not randomly or in an unstructured way, but more as a response to social and environmental factors present in the work environment (Tryon and Kleiner 1997). In the report "Applying the Brakes to Road Cargo Crime in Europe" (Europol 2009) is the complexity around insiders and drivers expressed: "Some estimates indicate a high level of driver involvement, but drivers are possibly the weakest link in the security of the supply chain. They are also the first line of defence and there is a need to train and educate them on cargo crime and personal safety issues whilst on the road." This leads to that the potential perpetrator both can be external to and internally involved in the supply and/or the transport chain.

"Organised theft of commercial vehicles and their loads in the European Union" (EP 2007) states the cost for cargo theft in the EU as "the total loss of value can be estimated at more than $€ 8,2$ billion each year. Of this amount about $€ 450$ million is not declared by the transport operators. If the loss value is related to the number of loaded trips, a value of about $€$ 6, 72 per trip results". As always, these numbers should not be taken as absolute regarding antagonistic threats, but the numbers presented in this report have more credibility than normal for this type of information. The report states that $41 \%$ of all incidents occurred during the driving phase of the transport while nearly $60 \%$ occurred during a stop. The two most commonly used methods are either threats toward the driver or tearing up of the canvas of the load unit. In $15 \%$ of incidents trucks are stolen with the goods, and another $15 \%$ is hijacking and robbery. According IRU (2008), the direct cost for an attack is approximately $€ 25000$ per attack, including theft of vehicles, load and the driver's personal belongings.

The UK home office presented its cargo theft situation in 2007 in "TruckPol Annual Report 2007" (TruckPol 2007). Cargo theft risk is higher in UK compared than the rest of the EU (EP 2007), with an average loss per incident of $€ 47,146$ (TruckPol 2007). This cost increased $14,6 \%$ from 2006 . The classification of the 2,284 recorded cargo thefts during 2007 was as follows: truck theft (51\%), theft from truck (28\%), attempted theft (7\%), hijack and attempts (4\%), deception (2\%), theft (other) $(7 \%)$, warehouse (1\%). Of the stolen trucks, almost half were recovered within $48 \mathrm{~h}$.

In Sweden does the attacks occurred mainly along the major roads and during night time. The most palpable findings in the official Swedish criminal statistics for freight related crimes is the $81 \%$ of all reported crimes attacked unprotected lorries or trailers (Nilsson and Rosberg 2009). There was a little reduction in number of stolen Lorries during 198 (2008) from 216 (2007) but the number of non-recovered Lorries was double to 26 (2008). The development for the theft of trailers is increasing from 105 (2007) to 135 (2008) where the number of non-recovered trailers increased by $25 \%$ to 25 (2008) (Nilsson and Rosberg 2009). The change in what types of goods are desirable depends more on the general change in customer demand. This means that the causality, from a crime displacement perspective, with regards to the stolen goods is very difficult to establish (Ekwall 2009b).

\section{Analysis}

The relationship between security and opportunity is the predominant understanding of security in different contexts (see Figure 1). This depends on the premise that 
security only can deter or repel a motivated perpetrator from committing a crime by limiting the opportunities for a certain crime. The most important thing to remember with crime opportunities is that an opportunity alone does not explain why a crime occurs because a crime needs a motivated perpetrator and opportunity to occur (Clarke and Cornish 2003). The real problem occurs when an organisation's security capability is lower than the capability of the motivated perpetrator. The official macro statistics indicates a few interesting things for the surroundings of transports in the EU. Firstly, the different levels of corruption in the different EU countries, where Denmark has the lowest level of corruption whiles Bulgaria, Greece and Malta has the highest level. This may indicate that the other official statistics from the more corrupted countries are less reliable. The statistics regarding homicide points our Estonia as the most dangerous country, with the rest (expect Malta) has about the same homicide frequency (around the EU average of 1.4). The grand total reported crimes as well as the more contexts related (for this paper) statistics points in most cases in the same direction as the two risk rankings indicates. The exceptions are Italy, Poland and Romania were the statistics and risk ranking provides a mixed image about the general threat level.

The official statistics about terrorist attacks in EU provides a clear picture, that terrorist activities in EU are closely related to geographical areas. If a transport just avoids areas like Corsica, the Basque Provinces and areas surrounding Marseilles, it also missed the areas where 85\% of all terrorist attacks occurred in EU 2006. Irrespective of this, it is important to remember that the predictability in crimes is lower and more far-fetched for terrorist crimes than regular property crimes. The main target for terrorist are the current political situation and transport activities is therefore only an indirect target as a terrorist perceives a freight as a valid target which will, in the perpetrators mind, lead to a change in the current balance of power in their regions.

The transport related statistics gives a more coherent picture of the problem with antagonistic threat against transports in the EU. This picture supports the routine activity perspective as a strong theoretical model for understanding the relationship between motivated perpetrators and the transports. Table 1 clearly demonstrates that the perpetrators use specific methods to attack transports in different parts of the transport chain. The insecure parking together with the near end location is the most risky parts of a transport chain for the business. According to Sherman (1995), crime will, in the future, be six times more predictable by location than by perpetrator. This statement is valid for antagonistic threats against transport indifference from other crimes due to the system predictability. It is easy to understand that predictable traffic movement of goods will attract criminals. A repeatedly used location provides desirable goods, the target for the perpetrators, which are hopefully guarded to some degree. The perpetrators can, from a system point-of-view, change location and method, the actual target (type of goods) has a lesser changing trend. This can depend on the fact that the type of goods that the thieves are interested in are decided by their customers instead of theft opportunities at transports. The similarity with the discussion about place of sale for illegal products is striking (Weisburd et al. 2006). With this said, the trend is that perpetrators change their modus operandi in order to steal the same type of products from transport.

Whiles the driving phase is exposed for the more skilled perpetrators as the modus there are Hi-jacks and different fraud tactics. The use of violence also seems 
to have increased in recent years. This can be a response to the implemented security countermeasures in transport. According to Saunders (2008) is it possible that "some perpetrators respond to sophisticates transport security measures by increasing their use of unsophisticated and brutal violence against drivers and terminal personnel". Similar development is expressed by EP (2007): The criminal organisations seem to react to the increase security with more aggressive methods.

The risk for loss varies greatly between the modes of transport. There is no surprise that trucks are most exposed to antagonistic threats. From a perpetrator point-of-view do road transports provide the most and the easiest exploited theft opportunities. The routine activity theory from criminology provides an excellent model for describing both why and how these antagonistic threats occur. The different sources of official statistics used in this paper clearly support this. The failure of countermeasures may be found in the different supply chain stakeholder's limitation to only see the risk within their own responsibility and thereby not applying a holistic approach (Ekwall and Lumsden 2007).

\section{Conclusion}

Where there is a logistics flow there is always a risk for having the goods stolen and the risk of antagonistic threats is related to the supply chain's wider environment. The holistic approach is useful when risk arises from the environment and a greater understanding of the cause is needed to reduce the total risk. The antagonistic threat is a risk that arises from the interior and the transport network's environment. This paper achieves this by focusing on the independent secondary data about criminal attacks against transport and then analysis with theory from criminology and supply chain risk management. Also, this paper does not attempt to break the problem down into its simplest parts, but instead by using a hard system approach provide a wide, multi-level analysis (see Figure 1). The risk of antagonistic threats differs between the network configurations according to the elements of crime. Different types of goods/products are shipped in the different configurations depending on the demands of their respective supply chain's requirements, whiles the transport movement are in general very predictable. The practical consequence of this is that the routine activities perspective is a valid theory for antagonistic threat which leads to that the potential perpetrator, in their pursuit of the right (desirable) object adjusts to the movement (routine) of the victim (transport elements like facilities and cargo carriers). The theft opportunity depends on the perpetrator's ability to use the routines of the target in combination with the lack of security at a certain location.

The economically driven antagonistic threats are subject to the supply and demand forces of the gray market, while non-economically driven antagonistic threats (terrorist activities) are linked to political/ideological/religious issues and both these types of perpetrators are linked to certain geographical areas or location. These driving forces, along with such opportunities as the unique combination of object, place, time, method, and security (or lack of), contribute to the risks and uncertainty in supply and transport chains.

This statistics do not provide a full image of the problem with antagonistic threats against transport in the EU but combining several independent statistical sources 
with a theoretical frame of reference establish a good understanding for the pattern and trends in this area. The analysis of the costs and shrinkage statistics in the official reports linked to primarily cargo theft indicates that the cost for having the problem may be lower than doing something to prevent thefts. This statement is only valid for the whole system; certain actors/stakeholder may very well be in a situation where it is cheaper to prevent the problem than to have it around. This may be one interpretation why antagonistic threats still exist today and probably will continue to be a part of transports risk environment, which lead indirect to the supply chain risk situation for involved actors.

The topic needs more attention from both academias as well as from the business itself. The different involved authorities have already increased their attention due to the implementation of different supply chain security programmes. But still is the holistic research approach missing. In order to understand and then prevent antagonistic threats is there a must that perpetrators are included in the analysis. This leads to that the in order to create new theories and knowledge about antagonistic threats must logistics research continues to elaborate with theories from other scientific fields.

\section{References}

Aastrup J, Halldórsson A (2008) Epistelmological role of case studies in logistics: a critical realist perspective. Int J Phys Distrib Logist Manag 38(10):746-763

Anderson B (2007) Securing the supply chain — prevent cargo theft. Security 44(No. 5):56-58

Barth S, White MD (1998) Hazardous cargo. World Trade 1998:29

Beck A (2002) Automatic product identification \& shrinkage: Scoping the potential. ECR Europe, Brussels

Beck A, Chapman P (2003) Hot spots in the supply chain: Developing an understanding of what makes some retail stores vulnerable to shrinkage. ECR Europe, Brussels

Borodzicz EP (2005) Risk, crisis \& security management. Wiley, Chichester

Bowersox DJ, Closs DJ, Cooper MB (2002) Supply Chain Logistics Management, 2nd edn. McGraw Hill/ Irwin series, Boston

Bruck T, Wickstrom BA (2004) The economic consequences of terror: guest editor's introduction. Eur J Polit Econ 20:293-300

Burns V, Peterson KD (2005) Terrorism-A documentary and Reference guide. Greenwood Press

Checkland PB (1999) System thinking, system practice-includes a 30-year retrospective. Wiley, Chichester

Christopher M (2005) Logistics and supply chain management—creating value-adding networks. Prentice Hall, London

Churchman CW (1968) The system approach. Dell publishing, New York

Clarke RV (1999) "Hot products: Understanding, anticipating and reducing demand for stolen goods", Police Research Series Paper, No. 112. Home Office, London

Clarke RV, Cornish D (2003) “Opportunities precipitators and criminal decisions: a reply to Wortley's critique of situational crime prevention". Crime Prev Stud 16:41-96

Clarke RV, Kemper R, Wyckoff L (2001) Controlling cell phone fraud in the U.S.: lessons for the UK'Foresight' prevention initiative. Secur J 14(1):7-22

Closs D and McGarrell E (2004) "Enhancing Security Throughout the Supply Chain". IBM Centre for the business of government

Cohen LE, Felson M (1979) Social change and crime rate trends: a routine activity approach. Am Sociol Rev 44:588-608

Dillén J and Ekwall D (2006) “Brott mot yrkestrafiken”. Transek 2006:10. (In Swedish)

ECMT (2001) Theft of goods and goods vehicles. CEMT/CM (2001)19, Lissabon

ECMT (2002) Crime in road freight transport. OECD Publication Service, Paris

ECR (2001) Shrinkage: Introducing a collaborative approach to reducing stock loss in the supply chain. ECR Europe, Brussels

ECR (2003) Shrinkage: a collaborative approach to reducing stock loss in the supply chain. ECR Europe, Brussels 
Ekwall D (2009a) Managing the risk for antagonistic threats against the transport network. Division of Logistics and Transportation, Chalmers University of Technology, Göteborg

Ekwall D (2009b) “The Displacement effect in cargo theft”. Int J Phys Distrib Logist Manag 39(1):47-62

Ekwall D and Lumsden K (2007) "Differences in stakeholder opinion regarding antagonistic gateways within the transport network". In proceedings of Nofoma, Rejkavik

EP-European Parliament's Committee on Transport and Tourism (2007) Organised theft of commercial vehicles and their loads in the European union. European Parliament, Brussels

EU (2003) "Freight Transport Security". Consultation paper. European Commission, Brussels

EUICS (2005) The burden of crime in the EU, A comparative analysis of the European survey of crime and safety. (EU ICS)

Europol (2007) EU terrorism situation and trend report 2007. The Hague, Netherlands

Europol (2009) Cargo theft report: Applying the brakes to road cargo crime in Europe. Europol, The Hague

Eurostat (2009) Criminal and criminal justice. Statistics in focus 36/2009

Felson M (1987) Routine activities and crime prevention in developing metropolis. Criminology 25(4):911-932

Felson M, Clarke RV (1998) Opportunity makes the thief: Practical Theory for crime prevention. Home office police and reducing crime unit, London

FATF (2010) Global money laundering and terrorist financing threat assessment. Financial Action Task Force, Paris, France

Francis TL (1986) A dynamic model of corruption deterrence. J Public Econ 31:215-236

Gammelgaard B (1997) "The system approach in logistics". In proceedings of Nofoma 1997, Copenhagen

Gammelgaard B (2004) Schools in logistics research? A methodology framework for analysis of the discipline. Int J Phys Distrib Logist Manag 34(6):479-491

Gearson J (2002) "The nature of modern terrorism”. The political quarterly publishing., pp 7-24

Gips M (2006) "Cargo security getting some respect”. Security management, July 2006, pp.28, ASIS International

Hellström D (2007) On interactions between packaging and logistics-exploring implications of technological developments. Division of Packaging Logistics, Lund University, Lund

IRU (2008) Attacks on drivers of international heavy goods vehicles. International Road Transport Union, Geneva

Johnston RB, Nedelescu OM (2006) The impact of terrorism on financial markets. J Financ Crime 13(1): $7-25$

Juttner U, Peck H, Christopher M (2003) Supply chain risk management: outlining an agenda for future research. Int J Phys Distrib Logist Manag 6(4):197-210

Kimball C (2002) When religion becomes evil. Harper, San Francisco

Klaus P, Henning H, Muller-Steinfahrt U, Stein A (1993) The promise of interdisciplinary research in logistics. In: Masters JM (ed) Proceedings of the twenty-second annual transportation and logistics educators conference., pp 161-187

Lab SP (2000) Crime prevention: Approaches, practices and evaluations, 4th edn. Andersson Publishing Co, Cincinnati

Lee HL, Whang S (2003) Higher supply chain security with lower cost: lessons from total quality management. Int J Prod Econ 96:289-300

Lowe P (2006) Counterfeiting: links to organized crime and terrorist funding. J Financ Crime 13(2):255-257

Lumsden K (2006) Logistikens grunder. Studentlitteratur, Lund, in Swedish

Mangan J, Lalwani C, Gardner B (2004) Combining quantitative and qualitative methodologies in logistics research. Int J Phys Distrib Logist Manag 34(7):565-578

Mankiw NG (1997) Principles of microeconomics. Dryden, Fort Worth

Manuj I, Mentzer JT (2008) Global supply chain risk management strategies. Int J Phys Distrib Logist Manag 38(3):192-223

Manunta G (1999) "What is security?”. Security journal, Vol. 12, No. 3, pp 57-66, Perpetuity Press

Muir J (1996) “Theft at work". Work Study; Vol. 45

Mustaine EE, Tewksbury R (1998) Predicting risk of larceny theft victimization: A routine activity analysis using refined lifestyle measures. Criminology 36(4):829-857

Napoleoni L (2004) Terror inc. Penguin books ltd

Nilsson P-A and Rosberg L (2009) "Polisens rapport on transportsäkerhet 2008". Polismyndigheten Västra Götaland \& Skåne (in Swedish)

Norrman A and Lindroth R (2002) 'Supply chain risk management: purchasers' vs planners' views on sharing capacity investment risks in the telecom industry". Proceedings of the 11th International Annual IPSERA Conference, Twente University, 25-27 March, pp. 577-95

NRSS (2002) National Retail Security Survey. University of Florida 
Nuzzo A (2004) Reasons for conflict: political implications of a definition of terrorism. Metaphilosophy 35(3):330-344

Peste J (2003) Religion och terrorism: mellan samvaro och radikalis. Studentlitteratur, Lund, in Swedish

Rice JB and Spayd PW (2005) Investing in Supply Chain Security: Collateral Benefits. IBM Centre for the business of government

Ritter L, Barrett JM, Wilson R (2007) Securing global transportation networks. McGraw Hill, NY

Robinson PV (2009) "Freight crime in Europe: what happens next?". A presentation at ESCB 09, Prague

Roncek DW, Maier PA (1991) Bars, blocks, and crimes revisited: linking the theory of routine activities to the empiricism of "hot spots". Criminology 29(4):725-753

Ruijgrok C, Wandel S, Nemoto T (1991) “Advanced Logistics and Road Freight Transport”, OECD Road Transport Research, Chapter IV

Rystad G (2006) Politiska mord - det yttersta argumentet. Historiska media, Lund, in Swedish

Sampson R, Eck JE, Dunham J (2010) Super controllers and crime prevention: a routine activity explanation of crime prevention success and failure. Secur J 23(1):37-51

Sarathy R (2006) "Security and the global supply chain". Transportion journal, fall, pp.29-51

Sarnecki J (2003) Introduktion till kriminologi. Studentlitteratur, Lund, in Swedish

Saunders R (2008) "Increasing our vigilance". A presentation at TAPA Q1, Warwick

Sheffi Y (2001) Supply chain management under the threat of international terrorism. Int J Phys Distrib Logist Manag 12(2):1-11

Sherman LW (1995) Hot Spots of Crime and Criminal Careers of Places. In: Eck JE, Weisburd D (eds) Crime and place, vol 4, pp. Criminal Justice, Monsey, pp 35-52

Sherman LW, Gartin PR, Buerger ME (1989) "Hot spots of predatory crime: routine activities and the criminology of place". Criminology 27(1):27-55

Sjöberg L (2008) Antagonism, trust and perceived risk. Risk Manage 10:32-55. doi:10.1057/palgrave. rm.8250039

Smith WR, And Frazee SG, Davison EL (2000) Furthering the integration of routine activity and social disorganization theories: small units of analysis and the study of street robbery as a diffusion process. Criminology 38(2):489-523

Stock JR (1997) Applying theories from other disciplines to logistics. Int J Phys Distrib Logist Manag 27 (9):515-539

Sweet K (2006) Transportation and Cargo security. Pearson Prentice Hall, New Jersey

TAPA (2006) TAPA Loss Data Benchmark Survey 2006

TE-SAT (2007) EU terrorism situation and trend report 2007. Europol, The Hague

Tilley N (1993) "Understanding car parks, crime and CCTV: Evaluation lessons from safer cities". Crime prevention unit series paper, No. 42. Home office, London

Transparency international (2009) Corruption Perceptions Index

TruckPol (2007) TruckPol Annual Report 2007. Homeoffice, TruckPol

Tryon G and Kleiner B (1997) "How to investigate alleged employee theft properly". Managerial auditing journal, Vol. 12, MCB University Press

UN (2002) United Nations surveys of crime trends and operations of criminal justice systems

Von Bertalanffy L (1969) General system theory-foundations, developments and applications. George Braziller, New York, First revised edn

Wandel S, Ruijgrok C (1995) "Information technologies for the development of transport and logistics". ATAS Bulletin information for development. United Nations, New York

Waples S, Gill M (2006) The effectiveness of redeployable CCTV. Crime Prev Community Saf 1:1-16

Waring A, Glendon I (1998) Managing risk. Thomson Learning, London

Weisburd D, Wyckoff LA, Ready J, Eck JE, Hinkle JC, Gajewski F (2006) Does crime just move around the corner? A controlled study of spatial displacement and diffusion of crime control benefits. Criminology 44(3):549-591 